\title{
Atrofia Hemifacial Progresiva: Presentación de un Caso Utilizando la Transferencia Microvascular de Epiplón
}

\author{
Carlos Centeno Ramírez, Gustavo Chavarría León *
}

Resumen: La atrofia hemifacial progresiva, mejor conocida como enfermedad de Romberg ha sido tratada por varios métodos reconstructivos convencionales que utilizan dermis, grasa, cartílago o músculo. Algunos autores han reportado el uso de transferencias libres microvasculares. Harii y Wallace describen la transferencia de un colgajo libre de epiplón. En este artículo, describimos un caso donde se utilizó la transferencia microvascular de epiplón para aumento de tejido blando facial. Este colgajo demostró tener vasos de adecuado calibre y longitud para la microanastomosis. La permanencia de septos, que mantienen bolsas aisladas en el lado reconstruido, minimiza la migración gravitacional de epiplón. El abordaje con dos equipos trabajando en cara y abdomen simultáneamente, redujo el tiempo operatorio. Este es el primer caso reportado de una corrección de atrofia hemifacial utilizando técnicas de microcirugía. Como en todo el mundo, en nuestro centro también las indicaciones para el uso de técnicas microquirúrgicas aumentan y ahora son más sofisticadas.

Descriptores: atrofia hemifacial, Enfermedad de Romberg, colgajo de epiplón.

La primera referencia histórica de la atrofia hemifacial progresiva la cual es un desorden sin aparente origen congénito, fue publicada en 1825 por Parry. En 1846 Romberg aisló como entidad clínica, un síndrome de etiología desconocida, caracterizado primariamente por una atrofia progresiva lenta en un lado de la cara. En esta entidad pacientes previamente sanos son usualmente afectados en la primera o segunda década de la vida con atrofia progresiva de piel, grasa, músculo, cartílago y a veces hueso. ${ }^{1} \mathrm{La}$ atrofia típicamente comienza antes de los veinte años de edad y es unilateral en $95 \%$ de los casos. ${ }^{2}$ Se han descrito varios procedimientos para corregir la atrofia hemifacial, entre los cuales se han realizado injertos de dermis grasa, ${ }^{3}$ inyecciones de silicón, ${ }^{4}$ injertos de cartílago,${ }^{3}$ colgajos pediculados cutáneos o miocutáneos, ${ }^{5}$ inyecciones de grasa lipoaspirada $^{6}$ y colgajos libres. ${ }^{7,8}$

Wallace, en 1979, reporta el primer caso de reconstrucción de atrofia hemifacial con un colgajo libre de epiplón, donde enfatiza la ventaja de poder disecar varios colgajos pequeños individualmente y la poca probabilidad de que exista contractura postoperatoria. $^{9}$

\footnotetext{
* Servicio de Cirugía Plástica y Reconstructiva, Hospital México.

Correspondencia:

Clínica Universal. Av 1 Calles 24 y 26. Paseo Colón.

Fax: 222-2520
}

16 marzo 1999, AMC, vol 41 (1)

\section{Presentación del Caso}

Paciente femenina de 22 años sin antecedentes familiares o personales patológicos de importancia, que inició su padecimiento un año y medio previo a nuestra valoración. Su enfermedad comenzó con una lesión grisácea de $4 \mathrm{X} 3 \mathrm{~cm}$ en la mejilla izquierda. Fue valorada por un dermatólogo, quien le administró un ciclo de triamcinolona, pero la enfermedad continuó en forma progresiva. El facultativo pensó que el empeoramiento de la enfermedad era debido a la terapia con esteroides. La paciente se presentó con atrofia hemifacial que comprometía mejilla, labio y mentón izquierdos (Figura 1).

Un día antes de la operación la paciente fue incluida en el protocolo de microcirugía que incluye:la colocación de un catéter central y periférico, administración de ASA, Persantín y Macrodex $40 \%$. Se decidió realizar la transferencia de un colgajo libre de epiplón.

Una vez esterilizadas las áreas quirúrgicas se colocó la paciente en decúbito supino para iniciar el procedimiento con dos equipos quirúrgicos. En la cara se realizó una incisión tipo ritidectomía, extendida inferiormente al ángulo de la mandíbula, para exposición de los vasos receptores que fueron la arteria y vena faciales. Se hizo una disección subcutánea del colgajo preservando las conexiones septales entre la dermis y la fascia, de manera que se mantienen tres bolsas independientes que 


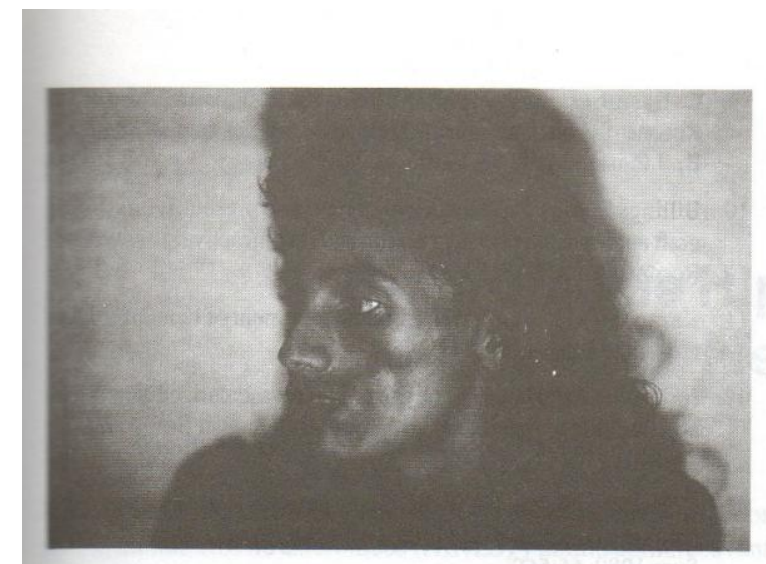

Figura 1: Paciente femenina de 22 años con atrofia hemifacial que compromete mejilla, labio y mentón izquierdos.

definen un área frontotemporal, zigomaticomaxilar y otra por arriba de la mandíbula. Al mismo tiempo que se levantaba este colgajo, el otro equipo obtenía el epiplón a través de una incisión de laparotomía. El epiplón se diseca del mesocolon transverso en un plano avascular dentro del saco menor, los vasos gástricos cortos anteriores y posteriores son individualmente ligados y cortados. Con la arcada gastroepiploica liberada de la curvatura mayor del estómago se toma la decisión en cuanto a la cantidad de epiplón que se debe transferir. La arteria gastroepiploica izquierda y dos venas comunicantes son ligadas, el epiplón entero es pediculado en base a la arteria gastroepiploica y está listo para transferencia a la cara. Se realizó la anastomosis microvascular de los vasos gastroepiploicos a los vasos faciales. Esta anastomosis fue hecha con técnica microquirúrgica utilizando un microscopio WILD M650 con objetivo de amplificación de 200x. En el postoperatorio la paciente evolucionó con dolor leve y moderado edema en el lado intervenido. A 6 meses de la cirugía el epiplón ha conservado un volumen adecuado que mejoró el volumen de la atrofia hemifacial (Figura 2).

\section{Discusión}

Varios procedimientos se han propuesto para mejorar las deformidades en la Enfermedad de Romberg, los injertos de cartílago y hueso proporcionan resultados limitados, porque sólo aumentan el volumen con una base ósea. ${ }^{3}$

Los injertos de grasa son rápidamente reabsorbidos, aunque se reportan estudios prometedores con técnicas de cultivo de células precursoras de adipocitos. ${ }^{10}$ También se ha utilizado para transplante la grasa, grasa y fascia, injertos dermograsos, grasa e injerto dérmico, grasa y fascia en bloque.

Se ha reportado que los injertos dérmicos y la fascia mantienen un mejor volumen que los transplantes de grasa. Todos estos procedimientos representan una medida temporal, sin control sobre el resultado final debido a la reabsorción. ${ }^{.1}$

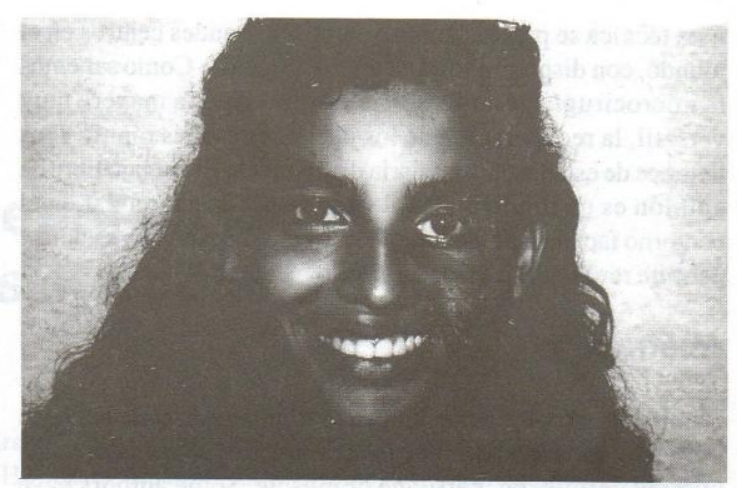

Figura 2: Paciente a los 2 meses de la cirugía muestra mejoria notable del contorno facial, luego de la transferencia microvascular de epiplón.

Un colgajo libre de piel desepitelizado es otro método de transferir grasa. Se han utilizado como sitios donadores el pie, antebrazo, escápula e ingle. En estos casos el pedículo puede ser corto y los vasos pequeños, y no ideales para un colgajo libre. Además una vez transplantados a la cara, se pueden recortar a lo ancho o a lo largo, pero no en grosor, por temor a comprometer la irrigación. ${ }^{12}$

A la paciente que presentamos se le realizó la transferencia de un colgajo libre de epiplón, para rellenar el defecto facial. El colgajo libre de epiplón fue descrito por Harii y Wallace para la corrección de deficiencias de tejido blando asociadas con atrofia y microsomía hemifacial. ${ }^{9}$

El defecto en nuestra paciente que comprometía mejilla, labio, mentón y región frontal izquierda, pudo ser bien rellenado con el colgajo de epiplón. Los vasos son de buen tamaño y el pedículo de adecuada longitud, para así no tener problemas con la microanastomosis. La caída gravitacional del epiplón se ha descrito como una complicación de esta técnica, por eso realizamos la recomendación de Upton y Mullicken de disecar tres bolsas faciales independientes. ${ }^{13}$ Otro problema relacionado con esta técnica, es que no se tiene una isla de piel para el monitoreo de la circulación del colgajo. Nosotros dejamos una ventana con una hoja de silastic transparente con fines de monitorización, pero consideramos que el método no fue confiable.

Otras complicaciones posibles incluyen una obstrucción abdominal secundaria a volvulus. En nuestro caso no tuvimos este problema, pero la aproximación cuidadosa del mesocolon transverso a la curvatura mayor del estómago, como sugiere Hakelius, puede evitar esta complicación. ${ }^{14}$

El abordaje con dos equipos trabajando simultáneamente en cara $\mathrm{y}$ abdomen redujo el tiempo operatorio.

Este es el primer caso reportado en nuestro país de la corrección de atrofia hemifacial utilizando una técnica microquirúrgica. 
Esta técnica se practica ampliamente en grandes centros en el mundo, con disponibilidad de microcirujanos. Como sabemos la microcirugía permite utilizar tejidos de una manera muy versátil, la recuperación de los pacientes es más rápida y los tiempos de estancia hospitalaria disminuyen. El colgajo libre de epiplón es un tejido maleable que se puede acomodar en el contorno facial, el procedimiento se puede hacer en un estadío y permite revascularización en el sitio receptor.

\section{Abstract}

Hemifacial atrophy, better known as Romberg disease, has been treated by several conventional reconstructive procedures which utilized dermis, fat, cartilage or muscle. Some authors have reported the use of microvascular free transfers. Harri and Wallace described the transference of a free vascularized omental flap. In this article we describe the transference of a free omental flap for augmentation of facial soft tissue. This flap has a long pedicle and large vessel size for microanastomosis. Retention of septae which keep pockets in the reconstructive side, minimized the migration of transfered omental tissue. The approach with two teams working simultaneosly at the face and abdomen, reduced the operative time.This is the first reported case in our country of the correction of facial hemiatrophy utilizing a microsurgical tecnique. This operation is practiced widely in many centers in the world where exist microsurgeon's avalability. As we know, microsurgery allow the utilization of tissues in a very versatile way, the recovery for the patients is faster and the patient hospitalization time decrease.

\section{Referencias}

1. Converse J.M Reconstructive Plastic Surgery. W.B. Saunders Company, 1977.

2. Mc Carthy J. Plastic Surgery. WB. Saunders Company. 1990.

3. Kazanjian VH,Sturgis SH. Surgical treatment of hemiatrophy of the face. JAMA 1940:115:348.

4. Rees TD, Ashlet FL,Delgado JP. Silicone fluid injections for facial atrophy: a ten year study. Plast Reconst Surg i 973; 52:118.

5. Converse JM,Betson RJ. A 20 year follow- up of a patient with hemifacial atrophy treated by a buried de- epithelized flap: a case report. Plast Reconstr Surg 1971; 48:258.

6. De la Fuente A., Tavora T. Fat injections for the correction of facial lipodistrophies : A preliminary report. Aesth Plast Surg 1988; 12:39.

7. Billings E, May JW. Historical review and present status of free graft autotransplantation in plastic and reconstructive surgery. Plast Reconstr Surg 1989; 83:369.

8. Wells JH, Edgerton MT. Correction of severe hemifacial atrophy with a free dermis-fat flap from the lower abdomen. Plast Reconstr Surg 1977; 59:223.

\section{8 marzo 1999, AMC, vol 41 (1)}

9. Callase J.G., Schneider W.J, Brown R.G., and Nahai FM. Reconstruction of hemifacial atrophy with a free flap of omentum. Br. J.Plast. Surg 32:15,1979.

10. Billings E, May JW. Historical review and present status of free graft autotransplantation in plastic and recontructive surgery. Plast Reconstr Surg 1989; 83: 369.

11. Kazanjian VH, Sturgis SH. Surgical treatment of hemiatrophy of the face. JAMA 1940; 115:348.

12. Jurkiewics MJ, Nahai F. The use of free revascularized flaps in the amelioration of hemifacial atrophy. Plast Reconstr Surg 1985; 76: 44-54.

13. Upton J, Mullicken JB, Hicks PD, Murray JE. Restoration of facial contour using free vascularized omental transfer. Plast Reconstr Surg 1980; 66:560.

14. Hakelius L. Fatal complication after the use of greater omentum for recontruction of the chest wall: case report. Plast Reconstr Surg 1978; 62: 796 .

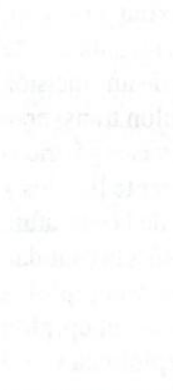

